\title{
Clinical criteria for the application of dry needling in myofascial pain Syndrome: An expert consensus document and a cross- sectional study among physical therapists
}

\begin{abstract}
Nicolas Secorro ${ }^{1}$ Rafael Guerra ${ }^{2} \quad$ Xavi Labraca $^{3}$ Marc Lari $^{4} \quad$ Daniel Pecos $^{5} \quad$ Bárbara Torres $^{6}$ Sandra Calvo ${ }^{10}$

${ }^{1}$ Grupo de Investigación iPhysio, Facultad de Ciencias de la Salud, Universidad San Jorge, Villanueva de Gállego, Zaragoza, Spain

${ }^{2}$ Clínica Rafael Guerra, Fisioterapia y Medicina Especializada, Getafe (Madrid), Spain

3 Instituto de Terapias NeuroMiofasciales, Barcelona, Spain

${ }^{4}$ Centro de Fisioterapia Inspira, Barcelona, Spain

${ }^{5}$ Grupo de Investigación Fisioterapia y Dolor, Departamento de Enfermería y Fisioterapia, Universidad de Alcalá, Madrid, Spain

${ }^{6}$ Fundación San Juan De Dios, Centro de Ciencias de la Salud San Rafael, Universidad Antonio de Nebrija, Madrid, Spain

Address for correspondence Sandra Calvo, PT, MSc, iPhysio Research Group, Universidad San Jorge, Campus Universitario, Autov A23, Km 299, 50830 Villanueva de Gállego, Zaragoza, Spain (e-mail: scalvo@usj.es).

Rev Fisioter Invasiva 2019;2:50-54.

Abstract

Keywords

- dry needling

- criteria

- trigger point

Presently, there is no clear consensus on the essential and confirmatory criteria which should govern the application of dry needling (DN) in the treatment of myofascial trigger points. The aim of this study was to generate a consensus on these criteria, via a panel discussion with DN experts which took place at the International Conference of Invasive Physical Therapy held in 2018, including the opinion of the attendees who participated in a live survey on the subject at the conference via an app. The results obtained reveal discrepancies regarding confirmatory criteria such as the elicitation of referred pain; nonetheless, consensus exists on the suitability of the application of individualized and personalized DN treatment and the combination of treatment with other intervention approaches in physical therapy, with the use of ultrasound when required to support a safer clinical practice.
\end{abstract}

\section{Introduction}

Dry needling (DN) is a physical therapy technique which consists of inserting a solid, filiform, non-beveled needle through the skin. The needle has a handle, and is made of stainless steel wire of variable diameter and length (ø: 0.16-$0.32 \mathrm{~mm}$; length: $13-100 \mathrm{~mm}$ ). This technique seeks the mechanical stimulus of needle insertion and manipulation, mainly aimed at the treatment of Myofascial Pain Syndrome (MPS). ${ }^{1}$

Myofascial Trigger Points (MTrPs) represent the target of techniques for the treatment of MPS as they are responsible for the group of signs and symptoms associated with MPS. ${ }^{2}$

received

November 20, 2019

accepted

December 6, 2019
DOI https://doi.org/

$10.1055 / \mathrm{s}-0039-3402788$. ISSN 2386-4591.
The different application modalities of DN can be classified in two large groups according to the depth of the needle in relation to the MTrP, this is superficial if the needle is maintained in the subcutaneous cell tissue nearby the hyperirritable nodule or deep if it crosses the sarcolemma of the muscle harboring the same. ${ }^{3}$

The mechanisms of action of deep DN include the rupture of dysfunctional motor end plates, a wash-out effect of the sensitizing substances accumulated in the MTrPs and the stimulation of descending inhibitory systems which regulate nociceptive processing. ${ }^{4} \mathrm{~A}$ complete regeneration of the injured area is considered to occur after seven days of
Copyright @ 2019 by Thieme Revinter

Publicações Ltda, Rio de Janeiro, Brazil
License terms

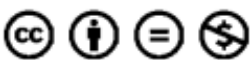


application of the technique, ${ }^{5}$ with no adverse effects found for repeated needling, provided the previously cited repair period is respected. Although different benefits are associated to DN, such as pain relief, increased range of motion and the improvement of muscle recruitment, ${ }^{6,7}$ the clinical criteria for its application vary among the different physical therapists who practice this technique.

The International Conference on Invasive Physical Therapy (CIFI), organized by the Scientific Society of Invasive Neuromusculoskeletal Physical Therapy (SOCIFIN), and held in Valencia in 2018 represented an opportunity to gather expert physical therapists in panel discussions on DN and clinical physical therapists with varying years of practical experience. This study, besides presenting the consensus of experts participating in the panel discussion on clinical criteria for the application of DN, features a cross-sectional study among the physical therapists who attended the CIFI 2018 with the aim of reaching conclusions which can be extrapolated to the clinical practice of the physical therapist in decision making for the use of this therapeutic modality.

\section{Material and Methods}

\section{Study Design}

A cross-sectional study was conducted with the data provided by the attendees of CIFI 2018, obtained via a survey comprised of 9 questions. The survey was developed previously based on brainstorming among physical therapists with extensive clinical experience in the application of dry needling ( $>5$ years) and the attendees of the panel of experts. Of the nine questions, the five first questions were of a more general nature to gather the sociodemographic characteristics of participants (-Table $\mathbf{1}$ ), whereas the remaining questions were divided into four thematic blocks - Table 2, to examine the opinion of attendees regarding DN and the clinical criteria for their application (-Annex 1), enabling the establishment of a small debate on the attendees' responses after each block:

1. Appropriate diagnosis and indication of DN as treatment;

2. Relevance of the MTrPs found, which should be treated?

3. Decision of the best treatment, adapted to the patient's characteristics, how to treat MTrPs?

4. Clinical criteria, once the decision to apply DN has been made.

The questions featured a single response, except for the last two questions, where multiple responses were allowed. The questions were displayed on the screen of the auditorium, together with the possible responses, using PowerPoint. In total, 204 people participated in the survey simultaneously after installing the "Votephone" App in their mobile phones or smartphones.

The panel of experts included the physical therapists Rafael Guerra, Xavier Labraca, Marc Lari, Daniel Pecos and Bárbara Torres, moderated by Pablo Herrero.

\section{Statistical Analysis}

For the statistical analysis, all the surveys were considered, independently of whether all responses were completed.
The data were exported to an Excel sheet for subsequent analysis via the IBM SPSS statistics program, version 23. According to the most recent records of the Spanish National Statistics Institute (INE), from 2012, there are 38,630 physical therapists who are registered in Spain. ${ }^{6}$ Thus, the study sample represented approximately $0.5 \%$ of this total population. 8

\section{Results}

Considering that all surveys were included in the statistical analysis, whether or not they had been fully responded, the total number of responses varied for the different questions. The results are divided into two parts: 1 ) the conclusions extracted from the debate generated in the expert panel discussion and 2) the data obtained from the sample performed to the attendees.

\section{Intervention of the Experts}

1) Provoking a patient's "referred pain" or "referred sensations" during DN was not considered an essential or fundamental diagnostic criterion on behalf of the participating experts, as the ability to reproduce the symptoms can depend on multiple factors, however it was considered as being an important confirmatory diagnostic criterion and a guarantee of therapeutic success. Other responses such as changes in tissue stiffness, despite not being indispensable, may also be of clinical interest.

2) Regarding the therapeutic relevance, the participants in the panel discussion considered that the selection and amount of MTrPs to be treated varies in each specific clinical case. In this sense, the first step that was approved is to identify the structure that generates the patient's pain by proposing several hypotheses which help to determine the responsible tissue. If the main hypothesis were a MTrP this would be classified as active and treatment of the same would be necessary. Thereafter, it would be beneficial to target treatment on latent MTrPs; as well as other tissues linked to the clinical condition of the patient and involved in the limitation of the joint range, loss of strength or motor control disorders, among others. Furthermore, in the sports context, patients may attend the consultation without pain, albeit with a sensation of discomfort, fatigue or lack of precision in certain gestures, a situation in which the sole treatment of latent MTrPs may be relevant. In addition, regarding the number of MTrPs to be treated with DN during each session, the experts considered that this was dependent on many factors, always with the premise of optimizing the use of invasive techniques (needling as little as possible) and adapting to the patient's needs, concretely to their priorities and expectations, tolerance to pain during DN or the time that the physical therapist has available to apply the treatment.

3) Regarding the duration of myofascial pain, there is no clear consensus advocating for clinical decisions to be 
52 Clinical Criteria for the Application of Dry Needling in Myofascial Pain Syndrome Secorro et al.

Table 1 Sociodemographic characteristics of attendees extracted from questions $1-5$

\begin{tabular}{|c|c|}
\hline Variables & N (\%) \\
\hline \multicolumn{2}{|l|}{$\operatorname{Sex}(n)$} \\
\hline Men & $105(71.92)$ \\
\hline Women & $41(28.08)$ \\
\hline \multicolumn{2}{|l|}{ Age (years) } \\
\hline $20-25$ & $18(10.78)$ \\
\hline $25-30$ & $36(21.56)$ \\
\hline $30-35$ & $40(23.95)$ \\
\hline $35-40$ & $41(24.55)$ \\
\hline $40-45$ & $23(13.77)$ \\
\hline $45-50$ & $9(5.39)$ \\
\hline $50-55$ & $0(0)$ \\
\hline $55-60$ & $0(0)$ \\
\hline$>60$ & $0(0)$ \\
\hline \multicolumn{2}{|l|}{ Work field (n) } \\
\hline Clinical & $160(90.4)$ \\
\hline Teaching & $6(3.39)$ \\
\hline Research & $2(1.13)$ \\
\hline Management & $4(2.26)$ \\
\hline Others & $5(2.82)$ \\
\hline \multicolumn{2}{|c|}{ Use of DN at the clinic (n) } \\
\hline Yes & $162(79.41)$ \\
\hline No & $19(10.5)$ \\
\hline \multicolumn{2}{|c|}{ Years of experience with DN (years) } \\
\hline$<5$ years & $60(35.71)$ \\
\hline $5-10$ years & $73(43.45)$ \\
\hline$>10$ years & $35(20.83)$ \\
\hline
\end{tabular}

Abbreviations: DN, Dry needling; $n$, number of subjects.

Descriptive statistics data.

individualized to each patient. In the cases of pain in the acute phase or of short evolution, treatment may be simplified, as, commonly, a large amount of MTrPs have not been developed, which, otherwise may be perpetuating the problem. However, in cases of chronic pain, the assessment is usually more complex and with the presence of a greater amount of MTrPs. Thus, the therapeutic choice should consider selecting a less intense treatment, although, at times, the treatment of a greater amount of MTrPs is required, thus avoiding the possible worsening of symptoms or a poor response to treatment. Addressing other etiological and perpetuating factors is key, according to the biopsychosocial model of pain.

4) Regarding the application of other intervention methods, the panel discussion coincided that the application of DN in combination with other techniques of physical therapy is essential, of which the most relevant techniques are manual therapy and active exercise.
Table 2 Frequency of votes for attendees - questions 6-9

\begin{tabular}{|l|l|}
\hline Question & $\mathbf{n}(\%)$ \\
\hline $\begin{array}{l}\text { P.6. Do you consider that provoking "referred pain" or } \\
\text { "referred sensations" to the patient during dry needling is an } \\
\text { ESSENTIAL diagnostic criterion? }\end{array}$ \\
\hline Yes & $85(50)$ \\
\hline No & $85(50)$ \\
\hline
\end{tabular}

P.7. Do you consider that the LTR is necessary for treatment with DN to be effective?

\begin{tabular}{l|l|}
\hline $\begin{array}{l}\text { I do not consider that it is necessary to } \\
\text { obtain LTR for the treatment to be } \\
\text { effective. }\end{array}$ & $16(9.82)$ \\
\hline $\begin{array}{l}\text { It is necessary to obtain at least 1 LTR. } \\
\text { I provoke several LTR, however I don't } \\
\text { believe that it is necessary to deplete } \\
\text { the appearance of LTR. }\end{array}$ & $22(13.5)$ \\
\hline $\begin{array}{l}\text { I try to provoke the maximum number } \\
\text { of LTR or until these are } \\
\text { depleted/disappear. }\end{array}$ & $13(7.98)$ \\
\hline
\end{tabular}

P.8. What factors do you consider are relevant when guiding the DN treatment? (Multiple response)

\begin{tabular}{|l|l|}
\hline Eliciting a LTR & 102 (58.96) \\
\hline $\begin{array}{l}\text { Obtaining changes in the stiffness of } \\
\text { the tissue during DN. }\end{array}$ & $90(52.02)$ \\
\hline $\begin{array}{l}\text { Reproduction of pain or symptoms that } \\
\text { are familiar to the patient. }\end{array}$ & $118(68.21)$ \\
\hline Others. & $21(12.14)$ \\
\hline
\end{tabular}

P.9 To what extent do you consider that the application of ultrasound-guided DN is necessary? (Multiple response)

\begin{tabular}{l|l|}
$\begin{array}{l}\text { In general, I do not see advantages to } \\
\text { the ultrasound-guided application of } \\
\text { dry needling. }\end{array}$ & 8 (4.52) \\
$\begin{array}{l}\text { I consider that, in some cases, ultrasound } \\
\text { guidance can present advantages in } \\
\text { terms of precision and/or effectiveness. }\end{array}$ & $136(76.84)$ \\
$\begin{array}{l}\text { I consider that, in some cases, ultra- } \\
\text { sound guidance enables a safer } \\
\text { application. }\end{array}$ & $155(87.57)$ \\
\hline
\end{tabular}

Abbreviations: DN, Dry Needling; LTR, Local Twitch Response; $n$, Number of votes.

Descriptive statistics data.

5) Considering the importance of obtaining the local twitch response (LTR) during treatment with DN, the experts agreed that, despite this not being essential for the diagnosis of MTrPs, the appearance of at least one LTR during the application of DN considerably increases the possibilities of confirming the diagnosis, as well as providing a greater effectiveness to the treatment, without the need to deplete the same and without consensus in the number of LTR which is considered recommendable. Regarding the controversy surrounding the therapeutic benefit of attaining a LTR, the experts added that, at times, the appearance of these responses is not necessary to obtain positive clinical results. 
6) On the appropriateness of ultrasound during the application of DN, the experts considered that the use of the same is essential for safety reasons in some of the muscle groups that are close to structures that risk injury. The use of the ultrasound also has the great advantage of enabling the visualization of the tissue and the LTR which occur during application, objectifying and quantifying the changes that are obtained in the area of intervention, which enables a follow up of the evolution of the patient at this level. However, the experts highlighted that the use of ultrasound presents certain disadvantages such as the loss of sensory information provided by palpation and the ability to apply pressure to secure the MTrPs during needling, and therefore, in the cases in which the use of the same is not essential, the physical therapists should be the one who decides, according to their criteria, which option is better for treatment. Regarding disadvantages, the large learning curve necessary for the use of ultrasound and the high cost of devices.

\section{Survey Performed to Attendees}

Of the total people surveyed, $72 \%$ of participants were men and the remaining $28 \%$ were women (58 people did not respond), of which, $35.71 \%$ had less than 5 years' experience, 43.45\% had between 5 and 10 years' experience and the remaining $20.83 \%$ had over 10 years' experience; 36 failed to respond. The age range of participants was between 20 and 50 years.

Concerning the field of work, $90.4 \%$ of participants reported working in the clinical sector, whereas 3.39\% corresponded to the teaching and $1.13 \%$ to research field and the remaining belonged to other sectors ( 35 failed to respond).

Concerning the clinical use of DN, $89.5 \%$ of those surveyed, applied this invasive technique on a regular basis, whereas $10.5 \%$ did not use it (23 did not respond).

Concerning the diagnosis of PGM, 85 people considered that provoking "pain or referred sensations" is an essential criterion, whereas the other 85 , had the opposite opinion (37 did not respond). Besides, $9.82 \%$ of participants did not feel that obtaining a LTR was essential for the effectiveness of treatment, whereas $13.5 \%$ stated that it was necessary to achieve at least one, $68.71 \%$ stated that it was necessary to provoke several, but without depleting them, and $7.98 \%$ responded that it was necessary to deplete these (45 did not respond).

In the last two questions with a multiple response, regarding the relevant factors guiding treatment with DN, eliciting a LTR received 102 votes, changes in tissue resistance received 90 , reproduction of pain was the most voted response, with 118 people, whereas other factors received 21 votes.

Concerning the need for applying DN under ultrasound guidance, only 8 people failed to find advantages to the use of ultrasound during DN, 136 considered that it may have benefits on the effectiveness or precision of treatment, whereas 155 people estimated that ultrasound is an element of safety during the application of the technique.

\section{Conclusions}

Although the physical therapists who attended the conference had a divided opinion regarding the classification of 'provocation of referred pain' as an essential criterion, the experts declared this as rather a confirmatory diagnostic criterion, considering the large number of factors that are considered when provoking pain.

Regarding the treatment of trigger points, there is consensus on the fact that treatment in the acute phase is considered more simple than in the chronic phase and that this treatment should be highly personalized and of a reasonable intensity to avoid sensitizing the patient and loosing effectiveness. This treatment should include interventions combined with DN such as physical exercise. During the invasive treatment technique, both the conference public and the experts tend to consider that the ability to elicit a LTR is not an essential criterion, however it does considerably increase the effectiveness of treatment.

Likewise, the use of ultrasound is proposed as an element of safety for interventions in delicate areas and for increased precision by enabling the real time visualization of the LTR in the tissue, despite the loss of palpatory information and a worse ability to secure the MTrP.

\section{Conflict of Interests and Source of Funding}

The authors declare no conflicts of interest nor commercial involvements with a direct financial interest in the results of this research.

\section{Acknowledgments}

To all the physical therapists who participated in the Fire Debates of CIFI 2018 in Valencia.

\section{References}

1 Valera F, Minaya F. Fisioterapia invasiva. $2^{2}$ ed. Barcelona: Elsevier España; 2017

2 Simons DG, Travell JG, Simons LS. Myofascial pain and dysfunction: the trigger point manual, The Upper Half of the Body. Vol. 1 second ed. Philadelphia, Baltimore: Lippincott William \& Wilkins; 1999

3 Baldry P. Superficial versus deep dry needling. Acupunct Med 2002;20(2-3):78-81

4 Shah JP, Gilliams EA. Uncovering the biochemical milieu of myofascial trigger points using in vivo microdialysis: an application of muscle pain concepts to myofascial pain syndrome. J Bodyw Mov Ther 2008;12(04):371-384

5 Domingo A, Mayoral O, Monterde S, Santafé MM. Neuromuscular damage and repair after dry needling in mice. Evid Based Complement Alternat Med 2013;2013:260806

6 Simons DG. Review of enigmatic MTrPs as a common cause of enigmatic musculoskeletal pain and dysfunction. J Electromyogr Kinesiol 2004;14(01):95-107

7 Shah JP, Thaker N, Heimur J, Aredo JV, Sikdar S, Gerber L. Myofascial Trigger Points Then and Now: A Historical and Scientific Perspective. PM R 2015;7(07):746-761

8 INE. Profesionales sanitarios colegiados 2012 [cited 2019 27/05]. Available from: http://www.ine.es/jaxi/Tabla.htm?path=/t15/ p416/a2012/\&file=s08002.px 


\section{Annexes}

\section{Annex 1 Survey provided to conference attendees}

1. Indicate your sex
1. Man
2. Woman

2. Indicate your age
1. 20 - 25 years
2. 25 - 30 years
3. 30 - 35 years
4. 35 - 40 years
5. 40 - 45 years
6. 45 - 50 years
7. 50 - 55 years
8. 55 - 60 years
9. Over 60 years

3. Indicate your main field of work
1. Clinical
2. Teaching
3. Research
4. Management
5. Other

4. Do you regularly use dry needling in your clinical practice?

1. Yes

2. No

5. How many years' experience do you have in the application of dry needling?
1. Less than 5 years
2. $5-10$ years
3. Over 10 years

6. Do you consider that provoking "referred pain" or "referred sensations" to the patient during dry needling is an essential diagnostic criterion?
1. Yes
2. No

7. Do you consider that the LTR is necessary for treatment with DN to be effective?

1. I do not consider it necessary to obtain an LTR for the treatment to be effective

2. It is necessary to obtain at least 1 LTR

3. I provoke several LTR, but I do not believe it is necessary to deplete the appearance of LTR

4. I try to provoke the maximum number of LTR or until these are depleted/disappear

8. What factors do you consider to be relevant when guiding DN treatment? (Multiple response)
1. Eliciting LTR
2. Obtaining changes in the stiffness of the tissue during DN
3. Reproduction of pain or familiar symptoms for the patient
4. Others

9. To what extent do you consider it necessary to apply DN under ultrasound guidance? (Multiple response)

1. Overall, I do not see advantages to the ultrasound-guided application.

2. I consider that, in some cases, ultrasound guidance can provide advantages in terms of precision and/or effectiveness

3. I consider that, in some cases, ultrasound guidance enables a safer application 